\title{
A Study to Find out Utility of Estimation of Serum CPK-NAC in Diagnosis and Prognosis of Electric Burn Induced Muscle Injury
}

\author{
Gupta Neelkamal $^{1}$, Sharma Brijesh Kumar ${ }^{2}$, Gupta Ritu ${ }^{3}$ \\ ${ }^{1}$ Assistant Professor, Department of Surgery, Mahatma Gandhi. Medical College \& Hospital, Jaipur (Rajasthan) India \\ ${ }^{2}$ Professor \& Head, Department of Surgery, Mahatma Gandhi. Medical College \& Hospital, Jaipur (Rajasthan) India \\ ${ }^{3}$ Senior Demonstrator, Department of Bioch Emistry, Dr, S. N. Medical College \& Hospital, Jodhpur (Rajasthan) India
}

\begin{abstract}
Introduction: Electric burn injuries constitute an important, distinct and often poorly understood variety of trauma. Muscles carry the highest percentage of current due to their large cross sectional area. CPK-Nac is a muscle specific isoenzyme of creatinine phosphokinase which increases in injuries of skeletal muscles. Thus the study was planned to find out the utility of CPK-Nac estimation in diagnosis and prognosis of electric burn injuries. Material and Method: The present study was conducted on 32 patients of electric burn in Department of Surgery, Mahatma Gandhi Medical College \& Hospital, Jaipur. The serum CPK-Nac levels were measured by enzymatic method in clinical laboratory of Biochemistry. Result and Discussion: The highest rate of complication was seen in patients with CPK-Nac value $>4000 I U / L$ while the lowest rate of complication was seen in patients with CPK-Nac value 0-1000IU/L. Conclusion: Estimation of CPK-Nac is simple, affordable, cost effective and available at most of laboratories so it should be included in the routine panel of investigations in every patient of electric burn as a diagnostic and prognostic index for evaluation of muscle injuries.
\end{abstract}

Keywords: CPK-Nac, Skeletal muscle, Electric burn, Creatinine phosphokinase, isoenzyme

\section{Introduction}

An electric burn injury is a result from electricity passing through the body leading to rapid injury. Approximately 1000 deaths per year due to electric burn are reported in United State with a mortality rate of $3-5 \%$. The severity of damage by electric burn is determined by four factors including voltage, current, resistance and frequency. The severity of burn also depends on the pathway; the current enters through the body.

In an electric burn, maximum tissue destruction occurs in the area adjacent to the contact point and is decreased as the distance from these points increases.

The electric current travels easily through skin, subcutaneous tissue and muscles due to high water content in these tissues. However electric current is not well transmitted through bone. Therefore, once the current strikes the bone, it travels along the bone through the associated muscle until it exits out through the skin at the distant site creating an exit wound. This leads to severe muscle damage along the route of the current travelled.

Creatinine phosphokinase (CPK) has three isoenzymes among them elevated level of serum CPK-Nac isoenzyme is a good marker of increased permeability of muscle membrane either to functional or mechanical damage to muscle cell membrane. Thus the present study was planned to estimate serum CPK-Nac level in electric burn patients with an aim to find out utility of this parameter in better prognosis and management of electric burn induced muscle injuries.

\section{Material and Methods}

The present study was conducted on 32 patients of electric burn in Department of Surgery, Mahatma Gandhi Medical College \& Hospital, Jaipur (Rajasthan). The age of the patients ranged from 11-40 years of age. 30 male and 02 female patients were included in the study.

An informed consent was taken from all the patients or their attendants who participated in the study after apprising them the nature and objective of study.

After routine management of electric burn patient, a blood sample was collected from each patient in plain vial for CPK-Nac estimation within 24 hours of electric burn.

Serum CPK-Nac levels were measured by enzymatic method in clinical Biochemistry laboratories. The procedure and methods described in kit manual were strictly followed.

\section{Observation Table}

Serum CPK-Nac level and percentage of complications

\begin{tabular}{|c|c|c|}
\hline S.No. & CPK-Nac Value & Percentage of complications \\
\hline 1 & $0-1000 \mathrm{IU} / \mathrm{L}$ & $16.67 \%$ \\
\hline 2 & $1001-2000 \mathrm{IU} / \mathrm{L}$ & $44.44 \%$ \\
\hline 3 & $2001-3000 \mathrm{IU} / \mathrm{L}$ & $50 \%$ \\
\hline 4 & $3001-4000 \mathrm{IU} / \mathrm{L}$ & $66.67 \%$ \\
\hline 5 & $>4000 \mathrm{IU} / \mathrm{L}$ & $75 \%$ \\
\hline
\end{tabular}

\section{Result and Discussion}

In the present study, the CPK-Nac values were found raised in cases that developed complications and were very 


\section{International Journal of Science and Research (IJSR) \\ ISSN (Online): 2319-7064 \\ Index Copernicus Value (2015): 78.96 | Impact Factor (2015): 6.391}

substantive and proportionate. The highest rate of complications was seen in patients with CPK-Nac values $>4000 \mathrm{IU} / \mathrm{L}(75 \%)$ followed by the patients with CPK-Nac values 3001-4000IU/L (66.67\%), patients with CPK-Nac values 2001-3000IU/L (50\%), patients with CPK-Nac values $1001-2000 \mathrm{IU} / \mathrm{L}(44.44 \%)$ and lowest rate of complication was seen in patients with CPK value $0-1000 \mathrm{IU} / \mathrm{L}$ (16.67\%).

The incidence of complications, surgical intervention and morbidity were high in patients with high CPK levels and as the level of CPK increased the rate of complications, surgical interventions and morbidity also increased.

Wang XW etal 1857 evaluated 26 patients with regards to CPK values in week one post burn and reported that CPK levels, especially with electrical and thermal burns and sensitive in evaluating the depth of burn injury.

Liu etal 2002 concluded that CPK-MM could be employed as the index for the infection and necrosis of muscle in electrical injured patients due to its high specificity and sensitivity.

Memon AR etal 2008 estimated serum CPK in burn injuries and found a statistically significant association between the lvel of serum CPK and likelihood of deaths $(p=0.0001)$. It was also suggested that serial monitoring of this enzyme can be used as prognostic indicator in the management of electric injuries.

Rhabdomyolysis due to trauma and burn is an important cause of acute renal failure secondary to myoglobinuria. To find out the utility of serum creatinine, creatine kinase and urinary myoglobin in detecting acute renal failure due to rhabdomyolysis in trauma and electric burn patients, Bhavsar P etal 2013 included 50 patients in their study and suggested that serum creatine kinase was raised in 14 of the 15 patients of acute renal failure (93.33\%).

\section{Conclusion}

Estimation of CPK-Nac is simple, affordable, cost effective and available at most of laboratories so it should be included in the routine panel of investigations in every patient of electric burn as a diagnostic and prognostic index for evaluation of muscle injuries.

\section{References}

[1] Wang XW, Jin RX, Bartle EJ and Davies JW (1987); Creatine phosphokinase values in electrical and thermal burns. Burns Incl. Therm. Inj. 13(4): 309-12.

[2] Liu, Shuhua, Xie and Weiguo (2002); Clinical significance of the change of serum CPK-MMin electrical injured patients. Chinese Journal of Burns. 18(4): 226-8.

[3] Memon AR, Tahir SM, Memon FM, Hashmi f and Shikh BF (2008); Serum creatinine phosphokinase as prognostic indicator in management of electric burns. $J$. Coll. Physician Surg. Pak. 18(4): 201-4.

[4] Bhavsar P, Rathod KJ, Rathod D and Chamania CS (2013); Utility of serum creatinine, creatine kinase and urinary myoglobin in detecting acute renal failure due to rhabdomyolysis in trauma and electric burn patients. Indian J. Surg. 75(1): 17-21. 